\title{
WHY THE READINESS POTENTIAL DOES NOT DISPROVE FREE WILL
}

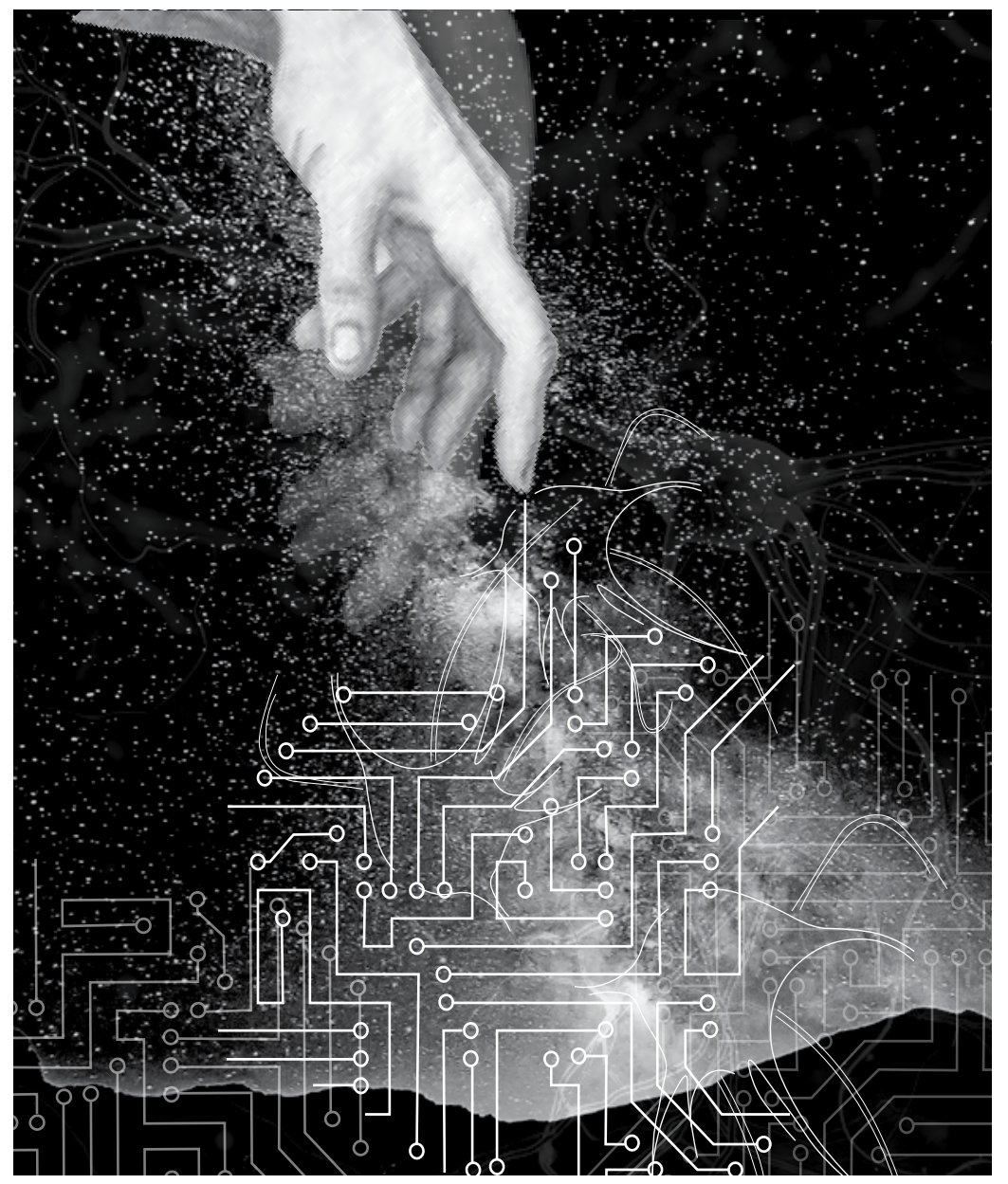

\section{ABSTRACT}

Neuroscientist Benjamin Libet has conducted a series of experiments that reveal the existence of certain neural processes in the brain of human subjects, initiating an action prior to the human subject's intention to act, thus seemingly threatening our idea of free will. The purpose of this paper is to show how these processes do not disprove any idea of free will one might have as one would, if accepting such a thesis, be committing two distinct mereological fallacies and ultimately, would treat the human subject as inhabiting some of its parts as opposed to being the sum of its parts.

EVEN TOTLAND 


\section{INTRODUCTION}

In 1982, neuroscientist Benjamin Libet conducted a series of experiments where his objective was to determine the exact time the brain of a human subject initiates an action and, subsequently, the time of the subject in question consciously deciding to perform the action as well as performing it. ${ }^{1}$ According to these findings, certain neural activities (called the readiness potential or RP) in the brain of the subject take place before the act is made and unbeknownst to the subject who only after a brief period after RP makes the conscious intention to act. Fully formed actions are thus organized in three consecutive stages: the readiness potential, the intention to act, and the act itself. Libet concludes that these results clearly indicate that "volitional" acts are not volitional at all since the brain would initiate them before the human subject forms the intention to perform the act. Free will could therefore be an illusion.

I aim to show that free will is not threatened by Libet's findings. His experiments are problematic because they are committed to an awkward form of dualism that includes two mereological fallacies. For the results to disprove free will, they must necessarily treat the human subject as consisting of two different substances, and Libet does so by privileging the subject's conscious awareness. Anything outside of this limited awareness, it follows, is given a property disconnected from the subject and treated as though not an authentic part of it. This is a peculiar commitment to make, even if there were a justification for it. While the results prove the existence of certain neural activities initiating an action before the subject's awareness of it, they do not prove that there is no free will. Thus, my critique is not directed at the existence of these neural activities, themselves, but rather at how one decides to consider them in relation to the human subject.

I start by summarizing the format and conclusions of Libet's experiment. Next, I present two arguments one might draw from Libet's conclusions and show that each commits a mereological fallacy.

\section{THE FORMAT OF THE EXPERIMENT}

Libet instructed the participants of his experiment to look at a moving dot that indicated the time and asked them to move their wrist at a time of their choosing, all the while their brain activity was monitored. They were so asked to make a personal note of the precise time-based on where the dot pointed - they had decided to move their wrist.

1 Benjamin Libet, "Do We Have Free Will?," in The Oxford Handbook of Free

Will, ed. Robert Kane (Oxford: Oxford University Press, 2003), 551, 10.1093/ oxfordhb/9780195178548.001.0001.
Libet noticed that each time the participants moved their wrist, the act was preceded by a "specific electrical change in the brain that begins $550 \mathrm{msec}$ before the act."2 This was called the "readiness potential" or RP. In addition to preceding the actual act by $550 \mathrm{msec}$, it also preceded the subject's intention to make the act by $350-400$ msec. The act itself took place ultimately $200 \mathrm{msec}$ after the subject had made the conscious intention to do it. A fully formed action was thus consecutively comprised of:

1. the readiness potential

2. the conscious decision to act 350-400 msec later

3. the performance of the act $200 \mathrm{msec}$ later

Parts (2) and (3) were conscious to the subject while part (1) was not. Libet concluded that these findings clearly indicated volitional acts to not be volitional. ${ }^{3}$ While these results could threaten the idea that humans have free will, Libet did not yet fully affirm this, and specified that the participants could decide not to make the act after becoming aware of the intention to do so: "The role of conscious free will would be, then, not to initiate a voluntary act, but rather to control occurrences of the act." An action could then consecutively look like this instead:

1. the readiness potential

2. the conscious decision to act

3. the subject deciding against performing the act

4. the subject not performing the act

For Libet, part (3) is where free will is taking place. The outcome in part (4) is therefore not as wholly determined by part (1) as implied in the first example. Though I grant that the human subject's ability to veto the act in (3) could be understood as an act of free will, I deny that the existence of RP negates free will. Thus, I argue that Libet does not need to resort to (3) to preserve our idea of free will.

\section{ASSESSING THE ARGUEMENTS}

Syllogistically, the first argument I draw from Libet is:

1. If human subjects' brains initiate an action before the human subjects make a conscious decision to so, then human subjects do not have free will

2. Human subjects' brains initiate an action before the humans make a conscious decision to do so

3. Therefore, human subjects do not have free will

2 Libet, "Do We Have," 551

3 Such a conclusion necessarily stems from an idea that part (1) is the determining factor in the act.

4 Libet, "Do We Have," 560 
There is, clearly, something queer about this argument. What or where, exactly, is the human subject supposed to be, and what is the irrelation to the brain? After all, the brain is a part of the human subject. So, how can it be that the brain is performing certain functions without the human subject? Such would be tantamount to the legs of a human subject walking without the human subject, but that is clearly nonsense. When we utter certain phrases like, "My leg is hurting," we do not mean that our leg has told us that it is hurting, and now, we express this hurt on behalf of it. The leg is not hurting, it is the human subject whose leg it is who is hurting.

This form of ascribing to the constituent parts of some attributes that logically apply only to the whole is often called a "mereological fallacy." When committing a mereological fallacy, one says things like, "The brain is thinking," not realizing that "thinking" can only be done by the human subject. As Bennett and Hacker write

It is not that as a matter of fact brains do not think, hypothesize and decide, see and hear, ask and answer questions, rather, it makes no sense to ascribe such predicates or their negations to the brain. The brain neither sees nor is it blind-just as sticks and stones are not awake, but they are not asleep either. The brain does not hear, but it is not deaf, any more than trees are deaf. The brain makes no decisions, but neither is it is indecisive. Only what can decide, can be indecisive. So too, the brain cannot be conscious, only the living creature whose brain it is can be conscious-or unconscious. ${ }^{5}$

Libet's argument commits the mereological fallacy by having the brain initiate an action when, in fact, the brain can do no such thing. Only the human subject can initiate an action, just like it is only the human subject who can walk, not their legs. This is a conceptual clarification, but there is a related scientific one as well.

When we think, it is tempting to say that we are thinking with our brain, as if the brain is the sole engineer in that enterprise. But the brain is only a segment in an otherwise intricate chain of processes that altogether constitute thinking. Putting a brain in a vat, as some epistemological thought experiments would have it, will not allow the brain to think. For the brain to have thoughts it needs oxygen transposed via blood vessels from the lungs. The lungs, themselves, need a respiratory system to obtain oxygen from outside the body. This, in turn, requires there to be oxygen to obtain from the outside. Cutting all these other components off from the act of thinking and having the brain pull the ship alone would yield disappointing results.

5 M.R. Bennett and P.M.S. Hacker, Philosophical Foundations of Neuroscience

(Oxford: Blackwell Publishing, 2003), 72.
Even designating the brain as the essential component of this process seems unfair and arbitrary. The essential component—or rather the essential whole-is the human subject in possession of all the faculties within a certain environment.

Realizing the absurdity of the previous argument, one could say that the neural processes compromising the readiness potential are simply subconscious, and that it is, hence, not initiated by the human subject consciously. In this way, we avoid the awkwardness of talking about the brain making decisions and trying to relate these to the human subject. Instead, we divide the human subject into an "inner amalgam" of the conscious and the subconscious. Syllogistically:

1. If human subjects are not conscious of the processes involved in their decision making, then they do not have free will

2. Human subjects are not conscious of the processes involved in their decision making

3. Therefore, human subjects do not have free will

This argument appears sounder than the previous one. In fact, it is precisely this type of argument Sam Harris is thinking of when he writes, "Consider what it would take to actually have free will. You would need to be aware of all the factors that determine your thoughts and actions, and you would need to have complete control over those factors." 6

But now, two questions emerge: What, exactly, are the necessary and sufficient conditions for something to be labeled conscious as opposed to subconscious and vice versa? Does the human subject as a whole have free will?

However, while the human subject is not conscious of the processes involved in their decision making - the subconscious claiming ownership of those processes - the subconscious too is a part of the human subject. Thus, the human subject is both the entity where the conscious resides and where the subconscious processes are taking place. In other words, a part of the human subject does not have free will because another part of the human subject is precluding that possibility.

Furthermore, how does one decide what experiences are to be classified as conscious as opposed to subconscious? Consider the act of walking; this act is often performed subconsciously. However, situations where walking is consciously performed are far from uncommon, so what do we classify walking as?

6 Sam Harris, Free Will (New York: Free Press, 2012), 32. 
One way to justify all of this would be to think of the human subject in a Cartesian fashion where some acts are thought to stem from a more authentic nature of the human subject, with all else being somewhat inessential. This more authentic nature is often termed "the self" and is what the pronoun, "I," is sometimes meant to point to. But how does one justify attributing the "I" only to that which is conscious? If the "I" is only to be found in the conscious part of the human subject, could we say that the subconscious part where these subconscious processes are happening, has free will? If so, a part of the human subject does have free will and saying, "I do not have free will," will thus have to mean that the "I" is separate from the human subject, while simultaneously being a part of it. This culminates in a paradox where the human subject both has and has not free will.

This move to a Cartesian dualism, where some arbitrarily selected segments of the human subject (those constituting the "conscious realm") are treated as an expression of its more authentic nature seems an utter misconception. "What is hopelessly confused is the supposition that the subject of experience is an entity within a human being."'

This argument, like the previous one, is guilty of committing some version of a mereological fallacy. This time, however, it is more informative to use Anthony Kenny's similar term, homunculus fallacy, "since its most naive form is tantamount to the postulation of a little man within a man to explain human experience and behavior."

The fallacy of the argument consists of treating the human subject as made up of (in this case) two homunculi where one is even depicted as being more important than the other and personifying the "real you" when in fact, "you" can be nothing but the whole of the human subject - or both homunculi, if you will. As with the designation of the brain as the essential component of thinking, the designation of which is taking place within the human subject's conscious realm as some essential nature of the human subject is unfair, arbitrary, and fallacious. Furthermore, the awkward dualism the argument promotes ultimately culminates in a paradox.

\section{CONCLUSION}

The main thesis of this paper is that Libet's experiment, powerful and admirably ambitious as it is, does not disprove free will. I assume, without further argument, that any definition of "free will" one might appeal to would not make his findings more likely to disprove it.

7 P. M. S. Hacker, Human Nature: The Categorial Framework (Oxford: Blackwell Publishing, 2007), 259.

8 Anthony Kenny, "The Homunculus Fallacy," in The Legacy of Wittgenstein (Oxford: Basil Blackwell, 1984), 125.
The first objection is against that of treating the brain as a subject for psychological predicates. The second is asking if it would, in any way, be justified to suggest that anything taking place subconsciously is less within the domain of the human subject as that which is taking place consciously. I have argued that it would not be justified to suggest that; the human subject is the sum of their parts and cannot be reduced to some of their parts. The questions of free will are deeply perplexing, but Libet's argument does not threaten any belief in the truth of free will. 


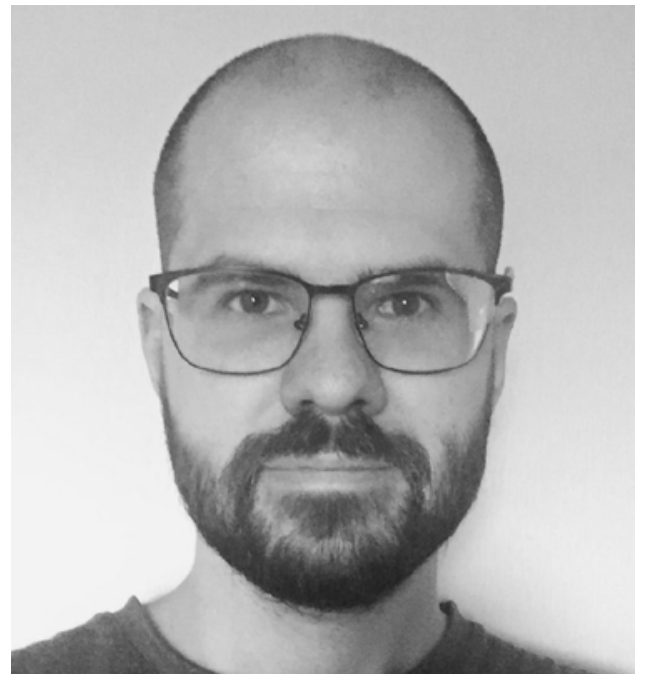

Even Totland is a student majoring in philosophy at the University of Bergen in Norway. Even's interests include philosophical methodology, logic, metaphysics, and issues in bioethics. 